\title{
CORRIGENDUM
}

\section{Long-term VEGF-A expression promotes aberrant angiogenesis and fibrosis in skeletal muscle}

\author{
H Karvinen, E Pasanen, TT Rissanen, P Korpisalo, E Vähäkangas, A Jazwa, M Giacca and S Ylä-Herttuala
}

Gene Therapy (2011) 18, 1180; doi:10.1038/gt.2011.93; published online 9 June 2011

Correction to: Gene Therapy advance online publication, 12 May The authors would like to apologise for this error. 2011; doi:10.1038/gt.2011.66

Since the online publication of this paper the authors have noticed that Figure 2 is incorrect. The Doppler data are missing in panels $\mathrm{i}$ and $\mathrm{j}$.

The correct figure is shown below.
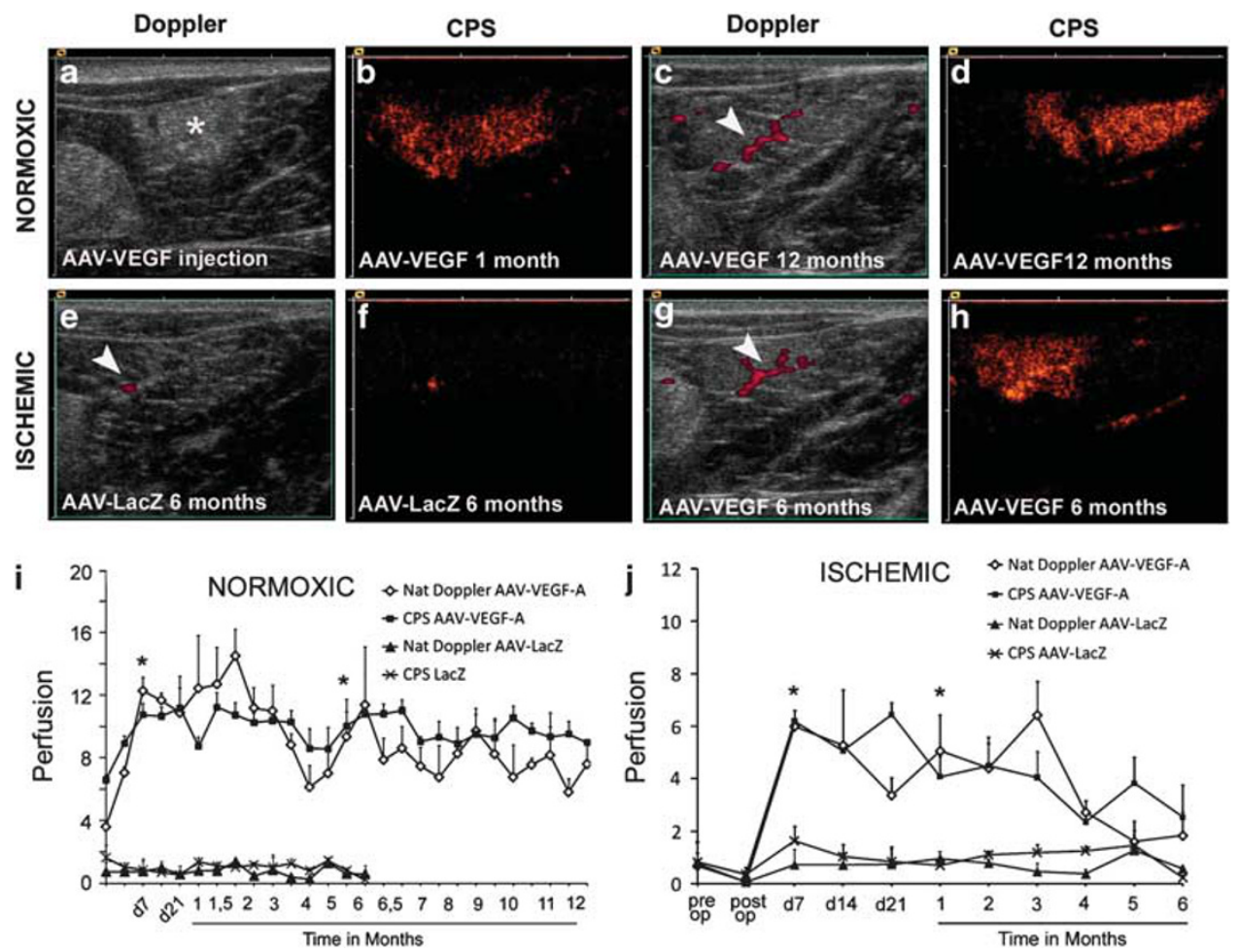

Figure 2 Muscle perfusion imaged by contrast pulse sequence (CPS) ultrasound technique in normal muscles (a-d) and after ischemia operation (e-h). Native image after AAV-VEGF-A-A 165 injection, asterisk indicates the location of the injection (a). CPS images from the same muscle 1 month (b) and 12 months (d) after AAV-VEGF-A-A 165 gene transfer. Power Doppler image after AAV-VEGF-A-A 165 gene transfer (c). Power Doppler (e) and CPS (f) images 6 months after ischemia operation and AAV-LacZ gene transfer. Power Doppler (g) and CPS (h) images 6 months after ischemia operation and AAV-VEGF-A$A_{165}$ gene transfer. Arrowheads in Doppler images indicate the signal from large vessels. Perfusion ratio to contralateral intact in normal muscles (i) and in ischemic muscles (j). Perfusion in VEGF-A-transduced muscle was increased compared with LacZ muscle already 1 week after gene transfer both in normoxic and in ischemic muscles. Results are presented as means \pm s.e.m., ${ }^{*} P \leqslant 0.05, n=3$. 